\title{
Keanekaragaman Mamalia di Cagar Alam Rimbo Panti, Kabupaten Pasaman, Sumatera Barat
}

\section{Diversity of Mammals at The Rimbo Panti Nature Reserve, Pasaman, West Suma- tra}

\author{
Tomi Kasayev ${ }^{1)^{*}}$, Jabang Nurdin ${ }^{1)}$ dan Wilson Novarino ${ }^{2)}$ \\ ${ }^{1)}$ Laboratorium Ekologi Hewan, Jurusan Biologi FMIPA Universitas Andalas \\ ${ }^{2)}$ Laboratorium Taksonomi Hewan Vertebrata, Jurusan Biologi, FMIPA Universitas Andalas \\ *Koresponden: tomikasayev7@gmail.com
}

\begin{abstract}
Rimbo Panti Nature Reserve is a conservation area located in West Sumatra which consisted of two main habitat types, dry hilly and swampy forest habitat types. These forest types potentially board many species of mammals. This research was conducted from December 2015 to March 2016 in The Nature Reserve to determine the diversity of mammals occupied each type of habitats. Twenty two camera traps were installed in pairs, six pairs in the dry hilly habitat (574-871 $\mathrm{m}$ asl) and five pairs in the swampy habitat (216-261 m asl). From a total 109 photos, 17 species were identified, consisted of 11 species from hilly and 10 species from swampy forest habitat. There were four species found in both habitat types. Shannon-Wiener diversity index showed that mammalian diversity of Rimbo Panti Nature Reserve is moderate $\left(\mathrm{H}^{\prime}=1.95\right)$ while mammalian diversity in swampy forest $\left(H^{\prime}=2.06\right)$ was higher than hilly habitat forest $\left(H^{\prime}=1.54\right)$.
\end{abstract}

Keywords : Camera Trap, Diversity, Dry Hilly Forest, Mammals, Swampy Forest

\section{Pendahuluan}

Cagar Alam Rimbo Panti merupakan salah satu kawasan konservasi yang ada di Sumatera Barat. Ditetapkan berdasarkan keputusan Gubernur Besluit No. 34 stbl 420 tanggal 18 Juni 1932 dengan luas sekitar 2.550 Ha. Kawasan ini memiliki dua tipe habitat berbeda yaitu habitat perbukitan dan habitat rawa (Sub Balai KSDA, 1999). Perbedaan dua tipe habitat tersebut memungkinkan cagar alam ini memiliki keanekaragaman fauna yang berbeda khususnya mamalia.

Habitat perbukitan pada penelitian Junaidi et al. (2012) di HPPB (hutan pendidikan dan penelitian biologi) Universitas Andalas ditemukan 10 spesies mamalia dari kelompok Primata, Pholidota, Rodentia, Carnivora dan Cetartidactyla, 23 spesies dari penemuan Hariadi et al. (2012) di Hutan Harapan Sumatera, dan beberapa spesies di tempat lainnya (Novarino et al., 2007; Novarino et al., 2010; Alfajri, 2010;
Mustari et al., 2015). Sementara di habitat rawa biasanya lebih cendrung ditemukan spesies yang berbeda dari habitat perbukitan, namun beberapa spesies juga ada yang menyukai kedua tipe habitat (Payne $e t$ al., 2000). Penemuan-penemuan tersebut tidak hanya digunakan untuk tujuan inventarisasi (Junaidi et al., 2012; Hariadi et al., 2012; Novarino et al., 2010), tetapi juga dapat memperkirakan populasi mamalia (Alfajri, 2010; Mustari et al., 2015; Wibisono, 2006; Pusparini, 2006; Maryani et al., 2014).

Khusus di Cagar Alam Rimbo Panti habitat perbukitan telah pernah dilakukan penelitian menggunakan camera trap di 4 titik pemasangan. Hasil penelitian menjelaskan bahwa Cagar Alam Rimbo Panti di habitat perbukitan memiliki 12 spesies mamalia. Namun beberapa spesies, populasinya dalam keadaaan terancam dan telah masuk kedalam status perlindungan 
Appendix I CITES, diantaranya Helarctos malayanus), Catopuma temminckii, Panthera tigris, Pardofelis marmorata (Novarino et al., 2010). Terancamnya keberadaan mamalia tersebut di Cagar Alam Rimbo Panti tidak lepas dari adanya aktivitas manusia. Dengan latar belakang tersebut, untuk itu pemantauan perlu dilakukan terhadap pelestarian keanekaragaman mamalia untuk dijadikan dasar pengelolaan manajemen konservasi yang lebih baik.

\section{Metode Penelitian}

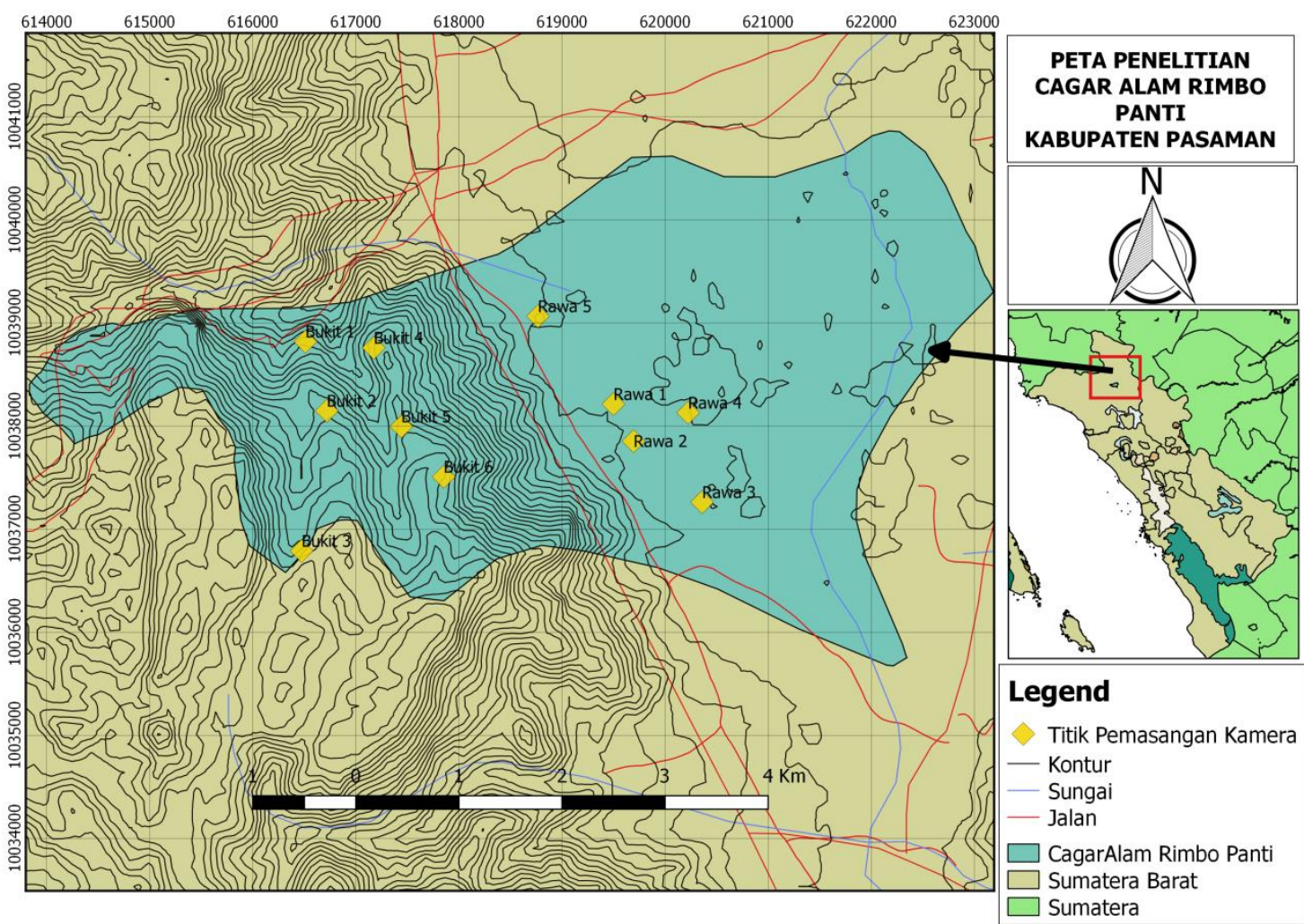

Gambar 1. Peta lokasi pemasangan camera trap di Cagar Alam Rimbo Panti. Inset : Peta Sumatera Barat

\section{Lokasi Penelitian}

Secara Geografis kawasan ini terletak antara $00^{\circ} 18^{\prime} 45^{\prime}$ ' LU - 00'22'30' LU dan $100^{\circ} 00^{\prime} 00^{\prime \prime} \mathrm{BT}-100^{\circ} 07^{\prime} 30^{\prime}$ ' BT. (BKSDA dan PSLH, 2000). Habitat perbukitan memiliki kondisi tanah yang terjal, kering, dan berkapur (kelerengan $>30^{\circ}$ ). Habitat rawa relatif datar dan memiliki genangan air $(0,5-1 \mathrm{~m})$. Didalam peta perbedaan tipe habitat ditandai dengan tipe kontur. Kontur yang sangat rapat adalah habitat perbukitan yang didominasi oleh vegetasi dari famili Euphorbiaceae, Annonaceae, Myrtaceae, Sapindaceae, Meliaceae, Lecythidaceae, Lauraceae, Moraceae, dan Myristicaceae, sedangkan kontur yang yang sangat jarang adalah habitat rawa yang didominasi oleh vegetasi dari famili Euphorbiaceae, Annonaceae, Moraceae, Macaranga,
Sterkuliaceae, Meliaceae, Murtifereae, Leaceae, Mirtaceae, Lauraceae, dan Fagaceae (Gambar 1).

\section{Cara Kerja}

Camera trap merupakan salah satu cara untuk mengetahui keberadaan satwa liar yang sulit dideteksi oleh pengamatan langsung (Maddox et al., 2004). Lokasi pemasangan kamera ditentukan dengan melihat tanda-tanda keberadaan hewan mamalia seperti jejak, kotoran, jalur habituasi secara purposive sampling. Camera trap dipasang sebanyak sebelas pasang. Enam pasang di habitat perbukitan dan lima pasang di habitat rawa yang di pasang selama 90 hari dan 1 x 45 hari untuk pengecekan. 
Camera trap dengan lensa autofocus aktif selama 24 jam dengan waktu antara setiap pemotretan satu menit yang terdiri atas tiga foto. Kamera dipasang pada pohon dengan ketinggian 40-50 $\mathrm{cm}$ dari permukaan tanah, sehingga mamalia yang melewati sensor terfoto secara otomatis. Foto tersebut diseleksi menjadi foto independen. Foto independen merupakan spesies mamalia (individu atau kelompok) yang terekam pada satu frame foto dalam satu rol film juga dalam blok sampel. Foto dianggap sebagai independent event (bernilai 1) jika: a) foto berasal dari individu berbeda (spesies sama) yang berurutan atau foto spesies berbeda yang berurutan, b) foto berurutan dari individu (spesies sama) yang jaraknya lebih dari 30 menit, kecuali individu dapat jelas dibedakan maka dianggap sebagai individu berbeda c) foto individu dari spesies yang sama yang tidak berurutan (Pusparini, 2006). Selanjutanya foto hewan mamalia diidentifikasi yang mengacu pada Payne et al. (2000) dan Corbet and Hill (1992)

\section{Analisis Data}

Komposisi jenis mamalia disajikan dalam bentuk grafik jumlah foto independen mamalia. Keanekaragaman spesies dari indeks Shannon-Wiener ( $H^{\prime}$ ) dihitung dengan rumus yang telah dimodifikasi dari Magurran (2004), $\quad H^{s}=-\sum_{i-1}^{s} P_{i} \operatorname{Ln} P_{i}$, dimana $P i$ adalah proporsi jumlah foto pada spesies ke- $i$ per total seluruh foto. Selanjutnya komposisi mamalia yang didapatkan dibandingkan dengan penelitian Novarino et al. (2010) yang dibandingkan secara deskriptif.

\section{Hasil dan Pembahasan}

Penelitian yang dilakukan di Cagar Alam Rimbo Panti didapatkan 109 foto independen. Foto tersebut terdiri dari 17 spesies (1 unidentified), 13 famili, dan 6 ordo. Dilihat dari jumlah spesies yang didapatkan tiap habitatnya, habitat perbukitan didapatkan 11 spesies (71 foto independen), sedangkan habitat rawa didapatkan 10 spesies (38 foto independen). Jumlah foto masing-masing spesies tiap habitat dapat dilihat pada Gambar 2.

Perbedaan jumlah spesies maupun jumlah foto yang didapatkan kemungkinan disebabkan oleh kondisi habitat yang berbeda, kondisi habitat perbukitan yang lebih kering dibandingkan habitat rawa yang sebagian besar digenangi oleh air. Spesies dengan jumlah foto independen terbanyak adalah Macaca nemestrina, kemudian dilanjutkan oleh Sus scrofa. Banyaknya foto kedua spesies tersebut pada penelitian ini, berbeda dengan hasil yang didapatkan pada penelitian yang dilakukan di Rimbo Panti tahun 2008. Pada penelitian sebelumnya, M. nemestrina merupakan spesies yang masih banyak terfoto, kemudian dilanjutkan oleh Hystrix brachyura. Sementara S. scrofa jauh lebih sedikit dibanding keduanya. (Novarino et al., 2010). Perbedaan ini bisa disebabkan oleh salah satu lokasi penempatan camera trap ditempatkan di area kubangan, sehingga menyebabkan S. scrofa banyak terfoto camera trap.

Didapatkan S. scrofa dan M. nemestrina, menurut Corbet and Hill (1992) kedua spesies ini memiliki penyebaran yang sangat luas. Hal ini diperkuat oleh temuan beberapa peneliti disekitar pegunungan bukit barisan, seperti Agustinus et al. (2009) di Taman Nasional Tesso Nilo, penelitian Alfajri (2010) di hutan Cagar Alam Malampah, penelitian Novarino et al. (2007) di hutan lindung Pesisir Selatan, penelitian Junaidi et al. (2012) di HPPB, penelitian Hariadi et al. (2012) di hutan bekas produksi Sumatera Selatan. Selanjutnya foto terbanyak dimiliki $H$. brachyura dan Tragulus napu, namun jumlah foto yang didapatkan jauh lebih sedikit dari $M$. nemestrina dan S. Scrofa. Foto tersebut didapatkan pada waktu malam hari dikedua tipe habitat. Novarino et al. (2007) dan Novarino et al. (2010) menjelaskan waktu aktif $H$. brachyura mulai pukul 18.00 sampai 06.00 WIB. Ditemukannya kedua spesies ini diasumsikan bahwa perbedaan tipe habitat sangat mampu ditolelir oleh kedua spesies ini, baik T. napu (Santosa et al., 2008) maupun H. brachyura (Kartono, 2015) 
Spesies Aonyx cinereus, Macaca fascicularis, Trachypithecus cristatus ditemukan di habitat rawa. A. cinereus ditemukan di sekitar anak sungai 1 hingga 7 individu. Spesies ini juga ditemukan dalam penelitian camera trap di areal rehabilitasi bekas tambang batubara, Kalimantan Tengah oleh Rustam dan Boer (2007) dimana di daerah tersebut ditemukan 4 individu dalam 2 foto, sedangkan penelitian di Taman Nasional Gunung Halimun Salak oleh Mustari et al. (2015) didapatkan 2 individu dalam 8 foto. Perbedaan jumlah individu yang didapat, diperkirakan disebabkan oleh kondisi habitat yang berbeda.

Untuk kedua spesies Primates $(M$. fascicularis dan $T$. cristatus), foto yang didapatkan sangat lebih sedikit dibandingkan dengan spesies Primates lainnya $(M$. nemestrina). Payne et al. (2000) mengatakan kedua primates ini lebih suka memakan buah-buahan dan dedauan serta lebih cendrung di atas pohon, sehingga perjumpaannya akan semakin sulit terdeteksi camera trap

Spesies Leopoldamys sabanus dan Sundamys sp. berasal dari famili yang sama yaitu muridae. Dua spesies tersebut didapatkan pada habitat perbukitan di dua lokasi pemasangan camera trap. Ketinggian kedua lokasi tersebut berkisar antara 726-
871 mdpl. Menurut Payne et al. (2000), L. sabanus nocturnal dan hidup di pepohonan hingga ketinggian 3100 mdpl dan Sundamys sp. sebagian besar nocturnal dan terrestrial hingga $1650 \mathrm{mdpl}$. Umumnya famili muridae tersebar dari perkampungan, dataran rendah hingga pegunungan di kawasan Asia Tenggara (Corbet and Hill, 1992). Handika et al. (2013) menemukan famili muridae di pegunungan Sumatera, Maharadatunkamsi (2011) Mustari et al. (2015) menemukan muridae di pegunungan Jawa, Suyanto (2008) menemukan muridae di pegunungan Kalimantan, Zakaria et al. (2001) menemukan muridae di pegunungan Malaysia.

Foto paling sedikit didapatkan selama penelitian adalah Herpestes sp., Mydaus javanensis, Muntiacus muntjac, Tupaia sp., Prionodon linsang dan Paguma larvata. Menurut Novarino et al. (2010) P. larvata adalah soliter dan sangat pemalu sehinggga keberadaan mereka sulit dideteksi. Payne et al. (2010) menambahkan $M$. javanensis, $P$. linsang juga spesies yang soliter dan pemalu. Foto paling sedikit lainnya ditemukan dari ordo Chiroptera (unidentified dan Cynopterus sp.) yang didapatkan di habitat rawa disekitar daerah rosting area.

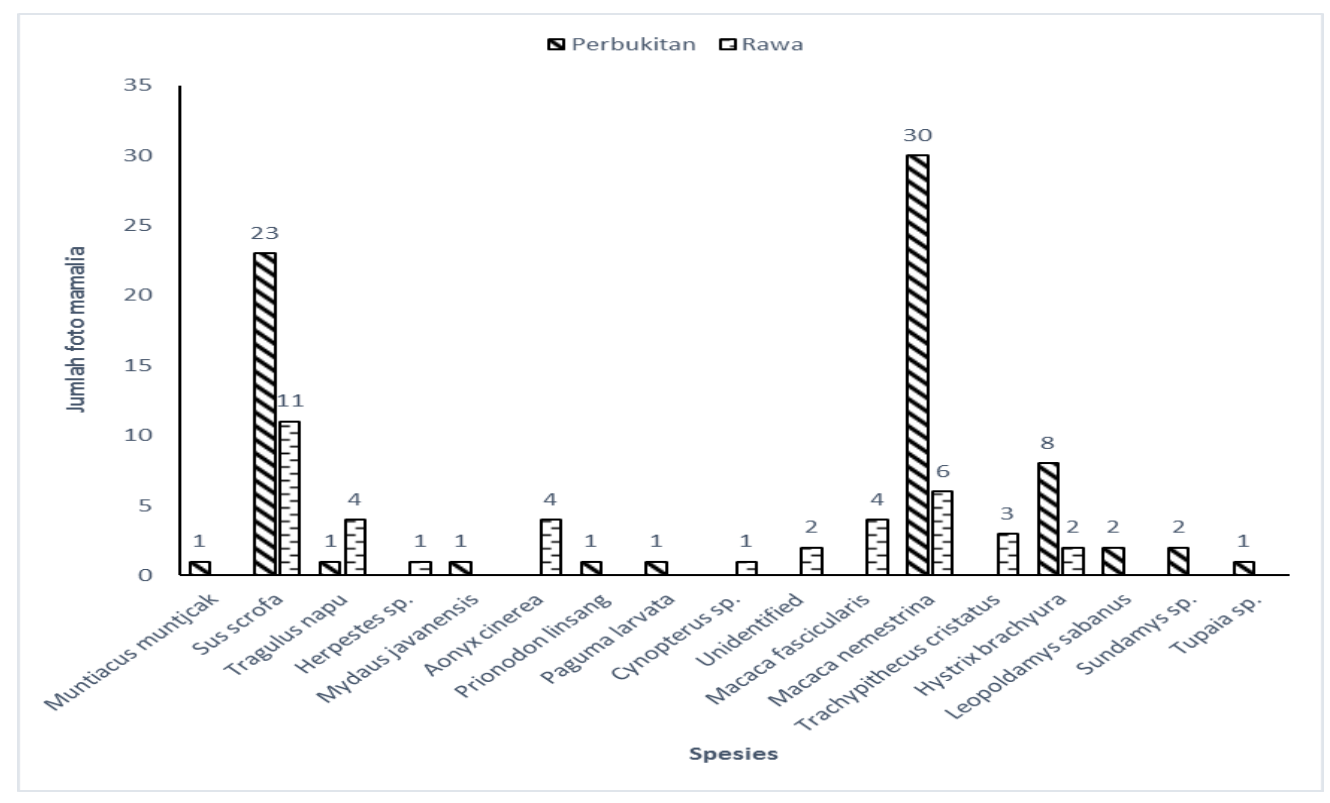

Gambar 2. Jumlah foto mamalia di Cagar Alam Rimbo Panti, Kabupaten Pasaman 
Berdasarkan hasil yang diperoleh, diketahui bahwa keanekaragaman spesies di Rimbo Panti dan pada masing-masing tipe habitat berbeda. Habitat perbukitan memiliki nilai indeks keanekaragaman 1,54 dan pada habitat rawa memiliki nilai 2,06. Secara keseluruhan indeks keanekaragaman di Rimbo Panti memiliki nilai 1,95. Perbedaan tersebut menurut penjelasan Magurran (2004) bahwa kedua tipe habitat cagar alam, dan di Rimbo Panti sendiri tergolong kedalam kategori tingkat keanekaragaman sedang.

Nilai keanekaragaman sangat tergantung pada beberapa faktor salah satunya yaitu faktor spesies dan jumlahnya. Menurut Kendeight (1980) dominasi spesies terhadap spesies lain akan menyebabkan rendahnya nilai keanekaragaman ataupun sebaliknya apabila jumlahnya merata maka nilai keanekaragaman akan tinggi. Selain itu, faktor terpenting yang mempengaruhi nilai keanekaragaman yaitu kondisi habitat. Menurut Susanto dan Ngabekti (2014) perbedaan habitat akan mendapatkan nilai keanekaragaman yang berbeda.

Berdasarkan Tabel 1. Dapat dilihat pada penelitian ini dipasang 6 lokasi di habitat perbukitan dan 5 lokasi di habitat rawa. Hasil yang didapatkan adalah 11 spesies di habitat perbukitan dan 10 spesies didapatkan di habitat rawa. Jumlah spesies yang didapatkan pada penelitian ini lebih sedikit jika dibandingkan pada penelitian 2008 yang mendapatkan 12 spesies di habitat perbukitan di 4 lokasi. Terjadi penurunan spesies dikarenakan adanya berbagai aktivitas manusia.

Tabel 1. Perbandingan mamalia di Rimbo Panti pada penelitian tahun 2008 dangan penelitian sekarang

\begin{tabular}{|c|c|c|c|}
\hline \multirow[t]{2}{*}{ Taxa } & \multirow{2}{*}{$\begin{array}{c}\text { Tahun } 2008 \\
\text { (Novarino, et al., 2010) } \\
\text { Perbukitan }\end{array}$} & \multicolumn{2}{|c|}{$\begin{array}{c}\text { Tahun } 2016 \\
\text { (Penelitian sekarang) }\end{array}$} \\
\hline & & Perbukitan & Rawa \\
\hline Macaca fascilularis & $\sqrt{ }$ & - & $\sqrt{ }$ \\
\hline Macaca nemestrina & $\sqrt{ }$ & $\sqrt{ }$ & $\sqrt{ }$ \\
\hline Helarctos malayanus & $\sqrt{ }$ & - & - \\
\hline Paguma larvata & $\sqrt{ }$ & $\sqrt{ }$ & - \\
\hline Catopuma temminckii & $\sqrt{ }$ & - & - \\
\hline Panthera tigris & $\sqrt{ }$ & - & - \\
\hline Pardofelis marmorata & $\sqrt{ }$ & - & - \\
\hline Sus barbatus & $\sqrt{ }$ & - & - \\
\hline Sus scrofa & $\sqrt{ }$ & $\sqrt{ }$ & $\sqrt{ }$ \\
\hline Tragulus napu & $\sqrt{ }$ & $\sqrt{ }$ & $\sqrt{ }$ \\
\hline Muntiacus muntjac & $\sqrt{ }$ & $\sqrt{ }$ & - \\
\hline Hystrix brachyuran & $\sqrt{ }$ & $\sqrt{ }$ & $\sqrt{ }$ \\
\hline Herpestes sp. & - & - & $\sqrt{ }$ \\
\hline Aonyx cinerea & - & - & $\sqrt{ }$ \\
\hline Prionodon linsang & - & $\sqrt{ }$ & - \\
\hline Unidentified & - & - & $\sqrt{ }$ \\
\hline Cynopterus sp. & - & - & $\sqrt{ }$ \\
\hline Mydaus javanensis & - & $\sqrt{ }$ & - \\
\hline Trachypithecus cristatus & - & - & $\sqrt{ }$ \\
\hline Leopoldamys sabanus & - & $\sqrt{ }$ & - \\
\hline Sundamys sp. & - & $\sqrt{ }$ & - \\
\hline Tupaia sp. & - & $\sqrt{ }$ & - \\
\hline Jumlah spesies & 12 & 11 & 10 \\
\hline Titik pemasangan & 4 lokasi & 6 lokasi & 5 lokasi \\
\hline
\end{tabular}

Penelitian 2008 ditemukan hewan kharismatik (Panthera tigris) yang termasuk terancam sebanyak 2 foto, namun pada penelitian ini tidak ditemukan kembali hewan kharismatik walaupun jumlah lokasi pemasangan camera trap sudah lebih banyak. Selain itu, spesies lain yang keberadaannya sudah mulai terancam juga tidak ditemukan pada penelitian ini, seperti Helarctos malayanus, Catopuma temminckii, Pardofelis marmorata, dan Sus barbatus. Menurut Alfajri (2010) berkurangnya perjumpaan hewan yang keberadaannya sudah terancam disebabkan 
karena adanya gangguan habitat oleh pemburu di kawasan cagar alam sehingga akan lebih sulit untuk ditemukan. Apabila kerusakan hutan dilakukan terus-menerus peluang berkurangnya komunitas mamalia sangat besar di Cagar Alam Rimbo Panti.

\section{Kesimpulan}

Berdasarkan penelitian yang telah dilakukan, dapat disimpulkan bahwa keanekaragaman mamalia di Rimbo Panti tergolong sedang $\left(\mathrm{H}^{\prime}=1,95\right)$, pada habitat rawa $\left(\mathrm{H}^{\prime}=2,06\right)$ keanekaragamannya lebih tinggi dari habitat bukit $\left(\mathrm{H}^{\prime}=1,54\right)$. Spesies paling yang paling banyak terfoto adalah $M$. nemestrina dan $S$. scrofa

\section{Ucapan Terima Kasih}

Terimakasih kepada kepala BKSDA Sumatera Barat yang telah memberikan izin penelitian. Keluarga Bapak Jamin yang telah membantu akomodasi di lapangan. Bapak Sakban, Sadam, Agung Nugroho, S.Si, M. M, Aadrean, M.Si, Dwiyanto, S.Si, M. Shobri hanif, S.Si, Andhika Prima Yudha, S. Hut, Erik Marlius, Fernando Dharma, S.Si, Setria Usman, S.Si yang telah membantu sebagai tim lapangaan.

\section{Daftar Pustaka}

Agustinus, S., M. H. Sinaga dan A. Saim. 2009. Biodiversitas Mamalia di Tesso Nilo, Propinsi Riau, Indonesia. Zoo Indonesia. 18(2): 79-88

Alfajri, D. 2010. Kelimpahan Harimau Sumatera (Panthera tigris sumatrae Pocock, 1929) di Suaka Alam Malampah Sumatera Barat. [Skripsi]. Padang. Universitas Andalas.

BKSDA-Sumbar dan PSLH-Unand. 2000. Rencana Pengolelolaan Cagar Alam Rimbo Panti Propinsi Sumatera Barat. Kegiatan pembinaan dan peningkatan usaha Konservasi didalam dan diluar kawasan hutan. DIK-S DR TA 1999/2000.

Corbet, G. B. and J. E. Hill. 1992. Mammals of the Indomalayan Region: A Systematic Review. Oxford University Press. Oxford. England.
Handika, H., J, Nurdin., dan Rizaldi. 2013. Komunitas Mamalia Kecil Terestrial di Gunung. Singgalang, Sumatera Barat. J. Bio. UA 2(2): 103-109.

Hariadi, B., W. Novarino, Rizaldi. 2012. Inventarisasi Mamalia di Hutan Harapan Sumatera Selatan. J. Bio. UA 1(2): 132-138.

Junaidi, Rizaldi, dan W. Novarino. 2012. Inventarisasi Jenis-jenis Mamalia di Hutan Pendidikan dan Penelitian Biologi (HPPB) Universitas Andalas dengan Menggunakan Camera trap. J. Bio. UA 1(1): 27-34.

Kartono, A. P., I. Maryanto, dan M. H, Sinaga (2000). Keragaman mamalia pada berbagai tipe habitat di muaro bungo jambi. Media Konservasi: VII(1): 21-28.

Kendeigh, S.C. 1980. Ecology with Spesial Reference to Animal and Man. Department of Zoological Univercity of Illinoist at Urbana-Champaign. New Delhi. Pretince-Hall of India private Lomited.

Maddox, M.T, Priatna, D, Gemita, E dan Salampessy, A. Pigs, Palms, People and Tigers (Survival of The Sumateran Tiger in a Comercial Landscape). Jambi Tiger ProjectZoological Society of London, Report 2002-2004.

Magurran, A. E. 2004. Measuring biological diversity. Blackwell Publishing.

Maharadatunkamsi. 2011. Profil Mamalia Kecil Gunung Slamet Jawa Tengah. Biologi Indonesia 7(1): 171-185.

Maryani., A. Muhammad dan Sunarto. 2014. Estimasi Populasi Macan Dahan Sunda (Neofelis diardi) Di Suaka Margasatwa Bukit Rimbang Bukit Baling Menggunakan Bantuan Perangkap Kamera. JOM FMIPA 1(2): 362-370.

Mustari, A. H., A, Setiawan., dan D, Rinaldi. 2015. Kelimpahan Jenis Mamalia Menggunakan Kamera Jebakan di Resort Gunung Botol Taman Nasional Gunung Halimun Salak. Media Konservasi 20(2): 93-101. 
Novarino, W., S. N. Kamilah, A. Nugroho, M. N. Janra, M. Silmi dan M. Syafrie. 2007. Kehadiran Mamalia pada Sesapan (Salt lick) Di Hutan Lindung Taratak, Kabupaten Pesisir Selatan, Sumatera Barat. Biota 12 (2): 100-107.

Novarino, W., M. Silmi, Sriyono dan Oktawira. 2010. Jenis-jenis Mamalia di Cagar Alam Rimbo Panti. Biospectrum, 6(1): 41-45.

Payne , J., C. M. Francis, K. Phillipps, dan S. N. Kartikasari. 2000. Panduan Lapangan Mamalia di Kalimantan, Sabah, Serawak dan Brunei Darussalam. The Sabah Society Malaysia dan Wildlife Conservation Society Indonesia Program. Prima Centra. Jakarta.

Pusparini, W. 2006. Studi Populasi dan Analisis Kelayakan Habitat Badak Sumatera (Dicerorhinus sumatrensis, fisher 1814) di Taman Nasioanl bukit Barisan Selatan. [Skripsi]. Jurusan Biologi FMIPA UI.

Rustam dan C. D. Boer. 2007. Keragaman Jenis Mamalia di Areal Rehabilitasi Bekas Tambang Batubara PT. Kaltim Prima Coal Sangatta Kalimantan Timur. Rimba Kalimantan Fakultas Kehutanan Unmul 12(2): 135-142.

Santosa, Y., E. P. Ramadhan dan D. A. Rahman. 2008. Studi Keanekaragaman Mamalia Pada Beberapa
Tipe Habitat Di Stasiun Penelitian Pondok Ambung Taman Nasional Tanjung Puting Kalimantan Tengah. Media Konservasi 13(3): 1-7.

Sub Balai Konservasi Sumber Daya Alam Sumatera Barat. 1999. Buku Informasi Kawasan Konservasi Propinsi Sumatera Barat. Kegiatan Pembinaan dan Peningkatan Usaha Konservasi di Dalam dan Di luar Kawasan Hutan TA 1998/1999.

Susanto, A dan S. Ngabekti. 2014. Keanekaragaman spesies dan Peranan Rodentia di TPA Jatibarang Semarang. Jurnal MIPA 37(2): 115-122.

Suyanto, A. 2008. Keanekaragaman Mamalia Kecil di Hutan Lindung Gunung Lumut, Kabupaten Pasir, Kalimantan Timur. Zoo Indonesia 17(1): 16.

Wibisono, H. T. 2006. Population Ecology of Sumateran Tigers (Panthera tigris sumatrae) and their Prey in Bukit Barisan Selatan National Park, Sumatra, Indonesia. Thesis Master. The Department of Natural Resources Conservation, University of Massachusetts, Amherst, MA, USA.

Zakaria, M., S, Silang and R, Mudin. 2001. Species Composition of Small Mammals at the Ayer Hitam Forest Reserve, Puchong, Selangor. Pertanika J. Trap. Agric. Sci 24(1): 19 -22 . 